\title{
Internacionalização: balanço e desafios para a sociologia brasileira
}

\author{
Celi Scalon* \\ Richard Miskolci* *
}

\section{RESUMO}

O artigo apresenta um panorama da produção sociológica brasileira e sua disseminação desde a profissionalização a partir da segunda metade do século XX até o presente. Analisa a internacionalização em curso identificando suas principais características, analisa igualmente, em termos comparativos com outros países, como tem se dado a inserção da sociologia brasileira no cenário global. Por fim, discute alguns dos desafios para que nossa produção alcance maior reconhecimento internacional, como a adoção do inglês como língua de divulgação, a criação e consolidação de parcerias internacionais equitativas, a ampliação das pesquisas comparativas e o aumento da mobilidade docente.

Palavras-chave: sociologia brasileira; internacionalização; globalização; ciência; produção científica

* Professora Titular da UFRJ, Pesquisadora 1 A do CNPq, Cientista do Nosso Estado/ Faperj, membro do Executive Committee da International Sociological Association. Foi Coordenadora da Área de Avaliação da Pós-Graduação em Sociologia no Brasil, junto à CAPES (2014/ 2018) e Presidente da Sociedade Brasileira de Sociologia (2009-2011).

* * Professor Associado de Sociologia do Departamento de Medicina Preventiva da UNIFESP, Pesquisador do CNPq e coordenador do Quereres - Núcleo de Pesquisa em Diferenças, Direitos Humanos e Saúde (www.quereres.sites.unifesp.br). Foi Coordenador Adjunto da Área de Avaliação da Pós-Graduação em Sociologia no Brasil, junto à CAPES (2014/ 2018). 


\begin{abstract}
INTERNATIONALIZATION: APPRAISAL AND CHALLENGES FOR THE BRAZILIAN SOCIOLOGY
\end{abstract}

This article presents an overview of the Brazilian sociological production and its dissemination since its professionalization from the second half of the 20th century to the present. It analyzes the internationalization in progress, identifying its main characteristics as well as, in comparative terms with other countries, how the inclusion of Brazilian Sociology in the global scenario has taken place. Finally, it argues about some of the challenges for our production to achieve greater international recognition, such as the adoption of English as a language of diffusion, the creation and consolidation of equitable international partnerships, the expansion of comparative research and the increase of teaching mobility.

Keywords: Brazilian Sociology; Internationalization; Globalization; Sciences; Scientific Production

\title{
Introdução
}

$\mathrm{Na}$ última década, em meio à expansão do sistema nacional de pós-graduação, cresceu o interesse em ampliar a inserção e o impacto da sociologia brasileira internacionalmente. A despeito da rica produção sociológica que data desde ao menos a década de 1930, foi apenas na segunda metade do século XX que a formação de quadros nacionais passou a se dar de forma sistemática e profissional com a implementação de cursos de pós-graduação. Durante as primeiras décadas de criação dos programas de pós-graduação em Sociologia, boa parte dos quadros ainda foi formada no exterior, especialmente na Europa e nos Estados Unidos, onde então se concentrava a produção sociológica. Nesse período, os intercâmbios entre a sociologia brasileira e a desses centros se davam predominantemente "em mão única”, já que carecíamos de quadros, condições institucionais e apoio financeiro para nos articularmos a redes internacionais em condições equitativas.

Até a virada do milênio, o impacto internacional da sociologia brasileira foi restrito e tendeu a prover maiores intercâmbios com nossos vizinhos latino-americanos, com exceções, como a teoria da dependência desenvolvida na década de 1960 por Fernando Henrique Cardoso em parceria com Enzo Faletto e que teve repercussão mundial. Cardoso e Faleto trabalharam juntos na Comissão Econômica para a América Latina e o Caribe (CEPAL), portanto 
em um centro de pesquisa internacional especializado na América Latina. De forma diversa, a maior parte da produção sociológica brasileira engendrada no processo de formação de quadros profissionais das últimas décadas do século XX voltou-se para a compreensão da realidade nacional em um período em que era menor a inserção do Brasil na política internacional assim como a visibilidade de nossa ciência em termos mundiais.

Com o século XXI, em meio à forte expansão do sistema de pós-graduação brasileiro, ampliaram-se numericamente os programas de pós-graduação em sociologia pela maior parte do território brasileiro assim como a expansão também impulsionou o desmembramento de muitos programas de Ciências Sociais em um processo de especialização disciplinar. Além do aumento numérico e a maior cobertura geográfica da formação de quadros profissionais na área, cabe reconhecer como o aprimoramento do sistema de avaliação pela Coordenação de Aperfeiçoamento do Pessoal de Ensino Superior (CAPES) contribuiu para o avanço qualitativo da área de Sociologia. Atualmente, a grande maioria de nossos sociólogos é formada por programas nacionais, muitos dos quais incentivam estágios no exterior por meio de bolsas-sanduíche. Tais períodos curtos no exterior proporcionam aos pós-graduandos acesso a universidades e supervisores de pesquisa reconhecidos mundialmente, mantendo-os conectados à realidade brasileira e ao nosso mercado acadêmico.

No século XXI, portanto, aumentou o número e a qualidade dos programas de pós-graduação em sociologia, modificou-se nossa relação formativa com os antigos centros da produção sociológica e também houve uma expansão dos pós-doutorados e estágios sêniores no exterior, os quais contribuem para a atualização de nossos quadros e sua inserção em redes internacionais de pesquisa. O número de bolsistas CAPES em pós-doutorado quadruplicou nos últimos dez anos, considerando que em 2005 não existia a modalidade 'estágio sênior', para o cálculo foram somadas as bolsas pós-doutorado e estágio sênior, as quais, de fato, atendem o mesmo público de docentes-pesquisadores. As bolsas sanduíche aumentaram em maior proporção: quintuplicaram nos últimos dez anos. 
Gráfico1 - Dados sobre bolsistas CAPES em estágio sênior, pós-doutorado e doutorado sanduíche.

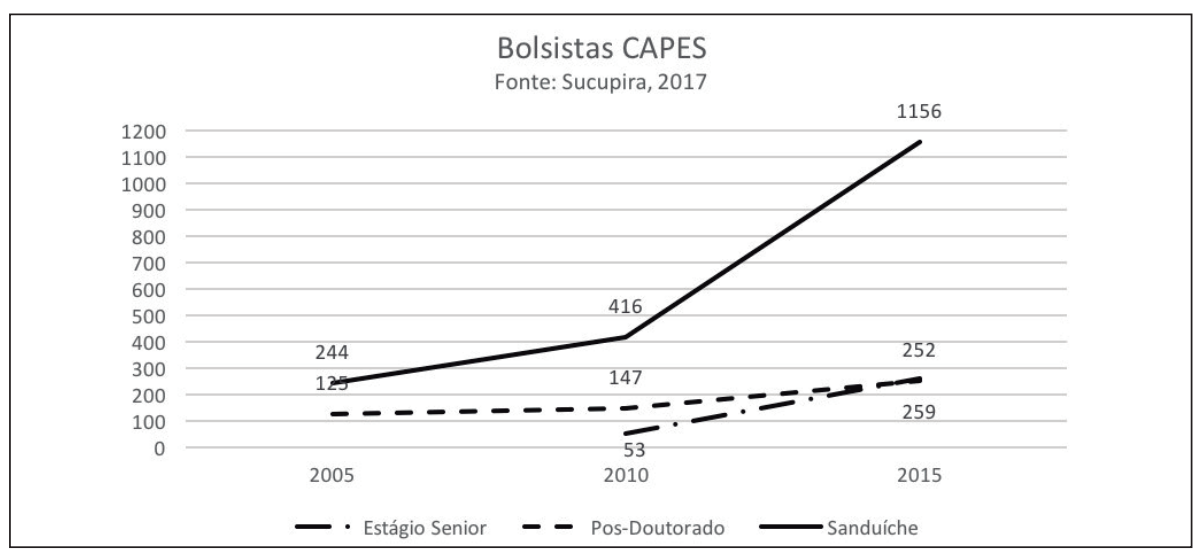

Fonte: Plataforma Sucupira, 2017

É nesse contexto que nossa área ampliou expressivamente sua inserção no cenário internacional por meio do crescimento da produção em periódicos e livros internacionais, da participação em diretorias de associações internacionais da área, em conselhos e comitês editoriais de periódicos internacionais, em grupos de pesquisa e formação profissional em rede internacional, em acordos e convênios internacionais, da presença de docentes e discentes em congressos e eventos científicos, entre outros. Essa crescente troca de conhecimento se manifesta por meio de pesquisas em rede internacional, pós-doutorados, doutorados e doutorados sanduíches, notadamente em países como Estados Unidos, Canadá, Inglaterra, França, Alemanha, Holanda, Espanha e Portugal; na América Latina com México, Argentina, Uruguai, Chile, Colômbia, Equador, bem como em países africanos de língua portuguesa.

Cabe salientar, também, o aumento da cooperação científica com o Japão e os países dos BRICS. Os esforços da Sociedade Brasileira de Sociologia (SBS) na aproximação e articulação com as associações profissionais dos países que compõem o bloco - China, Rússia, África do Sul e Índia - têm resultado em parcerias sólidas, reconhecidas e que contam com apoio financeiro e dos ministérios de relações exteriores desses países, configurando, atualmente, o BRICS University Network. O objetivo do Programa é reunir PPGs reconhecidos e recomendados pela CAPES, com nota igual ou superior a 6 (seis), inscritos por IES brasileiras para participar da Universidade em Rede do BRICS nas áreas prioritárias definidas: energia; ciência da computação e segurança da informação; estudos dos BRICS; ecologia e mudanças 
climáticas; recursos hídricos e tratamento da poluição; economia. O programa é financiado pelos governos dos cinco países e, no Brasil, a área de Estudos dos BRICS tem coordenação do Professor Tom Dwyer, da Sociologia da UNICAMP, que tem sido nos últimos dez anos o principal responsável pelo desenvolvimento dos estudos dos BRICS em nossa disciplina, liderando pesquisas e a produção de bibliografia em cooperação com esses países, sempre com o apoio da SBS. O projeto aprovado, que reúne UNICAMP, UFRGS e UFRJ, tem como objetivo central desenvolver conceitos e teorias próprias aos BRICS, que não obedeçam unicamente aos cânones dos grandes centros de produção sociológica, Europa e Estados Unidos da América.

A internacionalização está presente, ainda, na atração de alunos de pós-graduação em sociologia a partir do Programa de Estudantes-Convênio de Pós-Graduação (PEC-PG) da CAPES e também de países fora do programa, o aumento de cotutelas, especialmente com países europeus, e incorporação de estudantes de diversas nacionalidades.

Alguns dados são expressivos da consolidação da inserção internacional da área, que vem se constituindo como referência no cenário acadêmico internacional. O resultado acadêmico na Plataforma SCIVAL é medido pela métrica ASJC (All Science Journal Classification) usado na Scopus.

\begin{tabular}{|c|c|c|c|}
\hline Posição & País & Resultado acadêmico & Contagem de visualizações \\
\hline 1. & EUA & 30,799 & 348,190 \\
\hline 2. & Reino Unido & 12,460 & 159,359 \\
\hline 3. & Austrália & 5,117 & 83,951 \\
\hline 4. & Canadá & 4,607 & 59,879 \\
\hline 5. & Alemanha & 4,213 & 48,311 \\
\hline 6. & França & 3,277 & 21,845 \\
\hline 7. & Espanha & 2,932 & 44,250 \\
\hline 8. & Holanda & 2,786 & 45,380 \\
\hline 9. & Itália & 2,142 & 27,836 \\
\hline 10. & Índia & 2,120 & 14,080 \\
\hline 11. & Brasil & 1,618 & 11,768 \\
\hline 12. & Suécia & 1,525 & 21,028 \\
\hline 13. & China & 1,506 & 20,473 \\
\hline 14. & África do Sul & 1,272 & 10,851 \\
\hline 15. & Bélgica & 1,250 & 16,589 \\
\hline 16. & Federação Russa & 1,169 & 9,576 \\
\hline 17. & Israel & 1,109 & 11,543 \\
\hline 18. & Noruega & 1,092 & 13,999 \\
\hline 19. & Suíça & 1,068 & 13,169 \\
\hline 20. & Dinamarca & 1,023 & 13,460 \\
\hline
\end{tabular}

Fonte: SCIVAL, 2013-2015 
A tabela acima mostra que quatro países de língua inglesa constam no topo, indicando como o impacto do resultado acadêmico é ampliado pela divulgação em inglês, fato corroborado por outras tabelas sobre a produção de artigos científicos

\section{A internacionalização em um mundo globalizado}

Diversos países cuja língua nacional não é o inglês têm como uma de suas estratégias de internacionalização publicar sua produção científica nesta língua, caso da Suíça e da Holanda e, crescentemente, também da Alemanha. Em nosso país, o mais importante portal de periódicos - o Scielo (Science Library Online) - já publica mais periódicos em inglês do que em português e tem adotado política de progressiva disponibilização de conteúdo nessa língua entre as revistas de ciências humanas e sociais.

O aumento da publicação da produção sociológica em inglês tem se dado em um cenário complexo e, algumas vezes, contraditório. Há resistências e efetiva demanda por divulgação em português, assim como interesse crescente de pesquisadores em divulgar suas investigações a um público além de nossas fronteiras linguísticas. Os defensores da produção em português têm argumentos diversos, dentre os quais se destaca o enraizamento cultural de nossa sociologia (cf. ORTIZ, 2016). Essa resistência à adoção do inglês como língua franca vem, mais fortemente, das áreas de cultura e pesquisa etnográfica, em contraposição a áreas que trabalham com campos comuns internacionalmente, muitas vezes através de bancos de dados e informações compartilhadas, como, por exemplo, as áreas de Políticas Públicas, Direitos Humanos, Saúde, Estudos Urbanos, entre outras. Por sua vez, entre os que defendem a publicação em inglês, há um grande número de pesquisadores que encara seu horizonte profissional como inserido em redes internacionais adotando o inglês como língua de intercâmbio.

Além disso, a internacionalização se dá em um momento histórico marcado por questionamentos sobre geopolítica do conhecimento (CONNELL, 2015; MISKOLCI et al, 2016). Hoje sabemos que a disponibilização de conteúdo em inglês em um periódico local, por exemplo, não equivale necessariamente à internacionalização, assim como nem sempre um periódico estrangeiro nessa língua é efetivamente internacionalizado, o que pode torná-lo, inclusive, refratário a aceitar submissões vindas de fora de seu contexto 
científico. Fazendo frente justamente a este fato, a Sociedade Brasileira de Sociologia lançou, em 2015, a revista Sociologies in Dialogue, periódico com conselho editorial global, práticas editoriais internacionais e o objetivo de contribuir para intercâmbios intelectuais em âmbito mundial.

Dwyer (2013), com base no survey de 2009 com associados da SBS, aponta três dimensões importantes na internacionalização da Sociologia Brasileira. A primeira se refere ao país no qual os pesquisadores realizaram sua formação acadêmica e os dados mostram que a formação dos respondentes é, majoritariamente, realizada no Brasil. A segunda é a receptividade das ideias e, nesse caso, observa que os sociólogos brasileiros fazem uso intenso de autores estrangeiros e há no Brasil uma tradição de importação de livros. A terceira dimensão de internacionalização diz respeito à disseminação da produção científica de sociólogos brasileiros e, nesse caso, chama atenção sua baixa penetração no exterior. Avaliando os países com os quais o Brasil tem maior cooperação, ele conclui que a internacionalização da Sociologia brasileira se dá, primordialmente, pela relação com países próximos, em termos geográficos ou linguísticos; o que ele denominou "internacionalização estreita”, em oposição à "internacionalização ampla”, na qual se busca publicar e interagir com os países centrais. Apesar disso, ele enfatiza o recente processo de redirecionamento da internacionalização para o Sul Global, o que ele chama de "internacionalização ainda mais ampla”, uma vez que se refere aos esforços de cooperação com a Índia, a África do Sul e, mais recentemente, com a China. Nesse sentido, ele considera que “(...) a internacionalização da Sociologia Brasileira teria que se pautar na busca de responder a dois desafios: buscar construir o mais alto nível de diálogo científico, teórico e metodológico, com os sociólogos (e outros cientistas) nas mais variadas regiões do mundo; e ajudar atores sociais brasileiros relevantes a compreender e a agir neste novo e complexo mundo no qual habitamos" (DWYER, 2013, p. 83).

Em termos de publicação, a internacionalização não é simples sinônimo de publicar em inglês, mas divulgar o trabalho acadêmico em veículos com conselhos, políticas editoriais e audiências efetivamente globais. A rica produção sociológica nacional alcançará melhor seu potencial de impacto na comunidade internacional caso se direcione, ao menos em parte, para periódicos internacionais consolidados globalmente. Esforços de periódicos nacionais de se tornarem efetivamente internacionais também contribuem 
nesse sentido, dentre os quais se destacam iniciativas de publicação de números conjuntos com revistas com maior impacto mundial.

Nesse artigo, nos baseamos nos dados referentes à produção acadêmica brasileira e seu impacto no cenário mundial a partir das informações disponíveis na Plataforma SCIVAL. A plataforma SCIVAL não discrimina a área de Sociologia; nela, a Sociologia aparece classificada junto com a área de Ciência Política. No entanto, é revelador o crescimento das publicações brasileiras, considerando todos os tipos de publicações em periódicos, em coautoria com pesquisadores estrangeiros. A base de dados usada no SCIVAL é do Scopus.

Gráfico 2 - Resultado acadêmico por ano de publicação nas áreas de Sociologia e Ciência Política

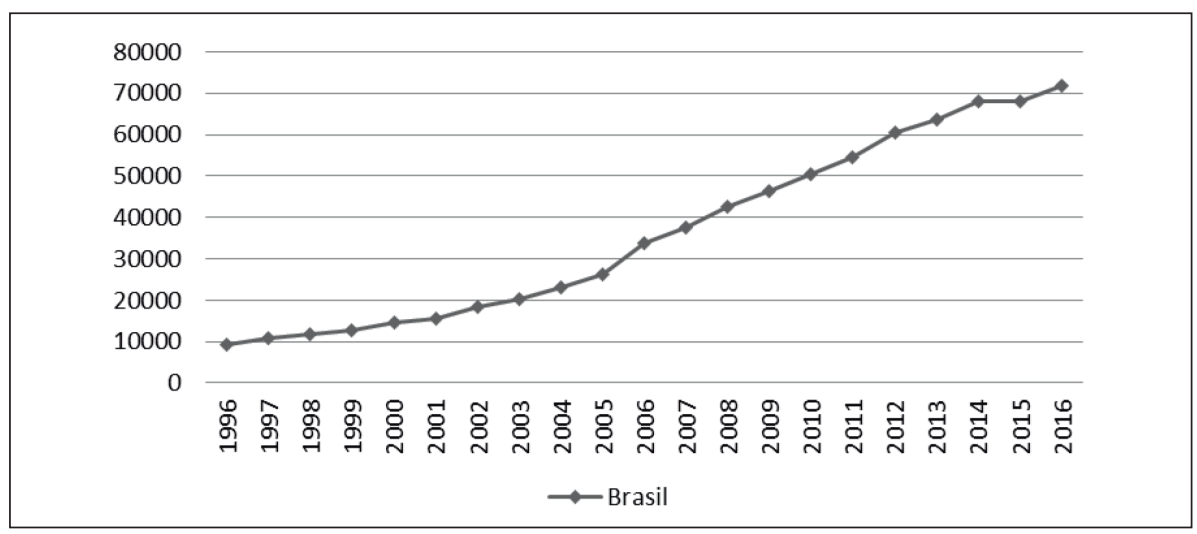

Fonte: SCIVAL, 2017

Apesar desse crescimento, há grandes desafios para que o Brasil se torne, de fato, um país integrado ao cenário acadêmico internacional. Verificamos que ainda estamos em uma posição de baixa produção internacional comparativamente a outros países, inclusive países que fazem parte do bloco dos BRICS e, portanto, estão em condições de renda e desenvolvimento próximos e, em alguns casos, condições mais desfavoráveis que o Brasil. 
Gráfico 3 - Resultado acadêmico por ano de publicação em quatro países (Brasil, Estados Unidos, Alemanha e França no período de 1996 a 2016

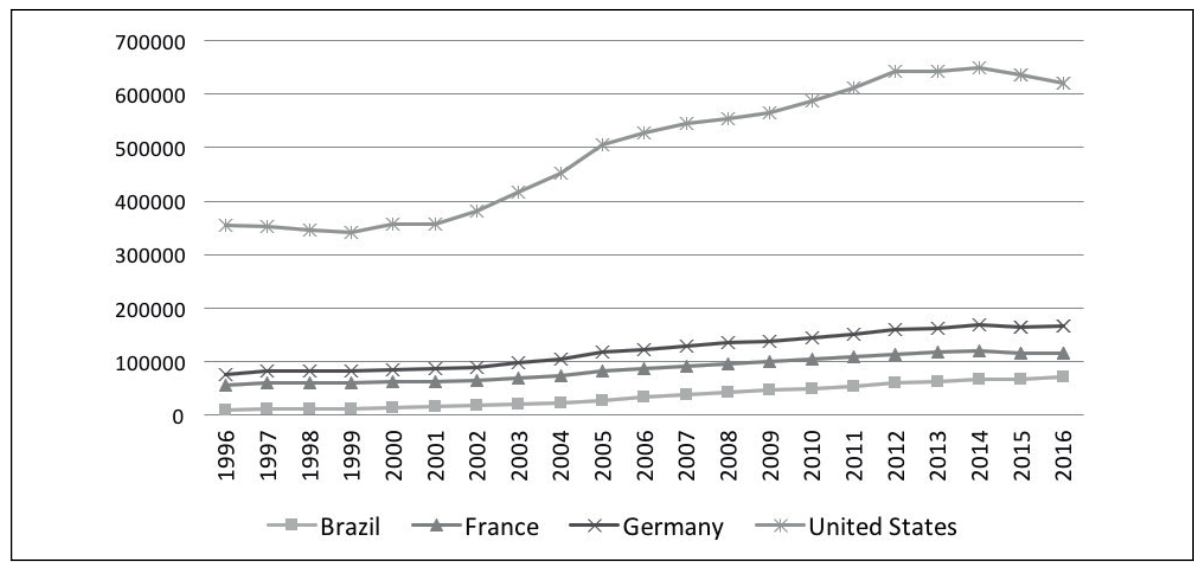

Fonte: Scival, 2017

O gráfico III insere países com produção acadêmica bastante consolidada e sabemos que as condições para inserção internacional da produção científica são muito desiguais entre os países do centro e da periferia e que os obstáculos não se resumem ao idioma. Por esse motivo, é interessante analisar os dados do Brasil em comparação com países do bloco dos BRICS.

Gráfico 4 - Resultado acadêmico por ano de publicação nas áreas de Sociologia e Ciência Política para os países BRICS.

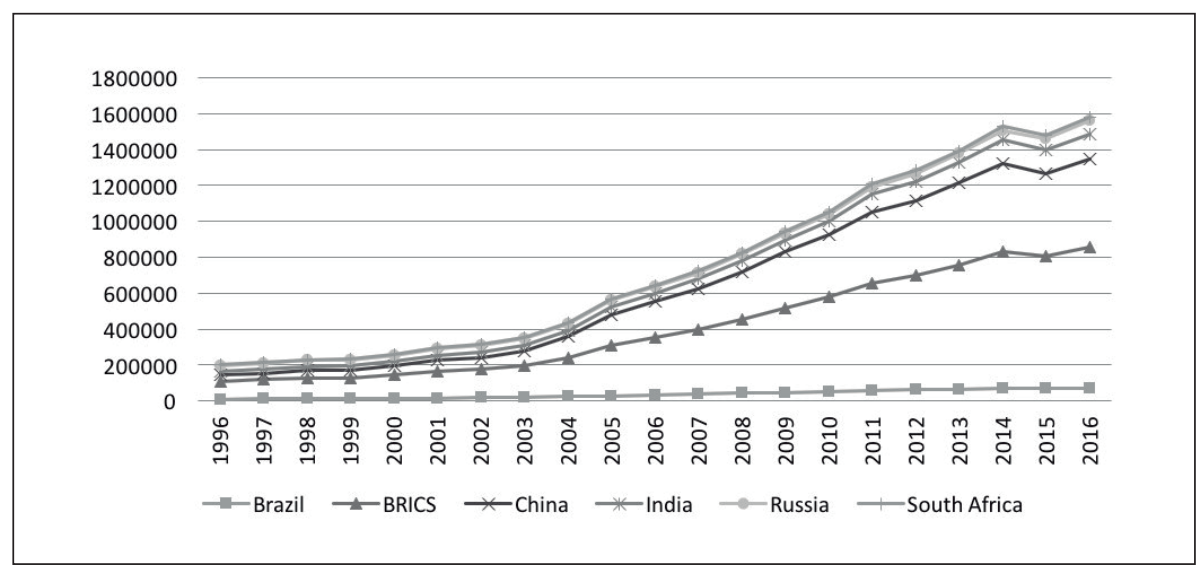

Fonte: SCIVAL, 2017 
Em suma, a internacionalização é um processo que deve ser ampliado e aprofundado permitindo a disseminação e troca de conhecimento em um mundo globalizado. A sociologia brasileira pode adotar estratégias diversificadas para alcançar maior consolidação em uma posição de destaque no cenário internacional, tais como: (a) direcionamento da produção para periódicos com impacto no âmbito internacional, tendo por meta o aumento da visibilidade e disseminação global da produção intelectual; (b) realização de pesquisas comparativas e acordos de cooperação, estabelecidos de forma simétrica e que possibilitem o desenvolvimento de paradigmas teóricos e metodológicos; (c) participação em eventos e estágios no exterior, especialmente de forma a estimular trocas mais contínuas como convênios, que permitam inserção efetiva de docentes e discentes em redes de pesquisa internacionais. Entendemos, desse modo, que a ciência brasileira deve ingressar no cenário acadêmico internacional em posição de parceria e liderança, evitando a histórica divisão do trabalho intelectual em que acadêmicos e pesquisadores europeus e americanos produzem teoria e métodos de pesquisa, enquanto os acadêmicos de países do sul global se dedicam a coletar dados, analisar estudos de caso ou pesquisa aplicada (MISKOLCI et al, 2016).

A avaliação quadrienal dos programas de pós-graduação em sociologia feita pela CAPES tem contribuído para o processo de internacionalização, já que considera a dimensão da inserção internacional de cada programa como resultado da qualidade científica do PPG. O aspecto principal é a qualidade dos periódicos utilizados para a divulgação dos resultados das pesquisas e o reconhecimento internacional pelos pares. Além das publicações, a qualificação internacional pode ser aferida pela participação dos quadros dos PPG na arbitragem de artigos e editoria de periódicos internacionais qualificados, pela participação por convite para apresentar, organizar, coordenar ou presidir eventos científicos relevantes na área, participar de bancas e Comitês de Avaliação no exterior, pela obtenção de financiamento com fundos internacionais, pelos projetos conjuntos e cotutela de teses, entre outros. Nesse sentido, cabe indicar a existência de programas de bolsas financiadas por instituições estrangeiras.

As ações que objetivam a internacionalização podem ser identificadas no volume e na qualidade dos acordos e cooperações para pesquisa e ensino com instituições estrangeiras de prestígio, na mobilidade de docentes e dis- 
centes, em atividades científicas no exterior, no oferecimento de disciplinas e cursos de âmbito internacional, na atração de estudantes estrangeiros para integrar o quadro discente dos programas, entre outros. Essas ações também se refletem nas atividades de melhoria da qualidade da escrita e da comunicação em inglês científico, que devem ser objeto constante da atenção dos sociólogos brasileiros.

Esse é um momento que pode ser especialmente vantajoso para acelerar o processo de internacionalização, uma vez que há preocupação dos governos com a obtenção de um lugar de excelência da produção científica brasileira na esfera global. Mas está claro que as estratégias de internacionalização para se tornarem viáveis dependem de apoio financeiro e condições institucionais e, na conjuntura nacional e mundial atual, esse é um ponto incerto.

No contexto dos Programas de Pós-Graduação, a área de Sociologia na CAPES define as notas 6 e 7 como atribuíveis, exclusivamente, para PPGs com doutorado que obtiveram nota final 5 e conceitos $\mathrm{MB}$ em todos os quesitos da ficha de avaliação e que tenham desempenho equivalente ao dos centros internacionais de excelência na área, nível de desempenho diferenciado em relação aos demais programas da área, solidariedade e capacidade de nucleação. Os Programas que atingem essas notas devem apresentar nível de qualificação, de produção e de desempenho equivalente ao dos centros internacionais de excelência na formação de recursos humanos, baseando-se principalmente nos seguintes indicadores: inserção na comunidade científica internacional; reconhecimento internacional da produção científica; reconhecimento da liderança internacional; intensidade da mobilidade internacional de docentes e discentes; liderança nacional e nucleação.

Para a análise destas características, devem ser observados alguns parâmetros, que são listados a seguir.

- Inserção na comunidade científica internacional: convênios e intercâmbios ativos firmados com instituições estrangeiras de reconhecido prestígio científico, em regime de reciprocidade e com divulgação no exterior; programas institucionais de cooperação internacional exigindo missões bilaterais de trabalho; realização, organização e participação em eventos científicos internacionais qualificados; prêmios internacionais (com láurea e/ou como participação em júris internacionais); consultorias a organismos internacionais; comitês editoriais e participação como pareceristas em periódicos internacio- 
nais; redes internacionais de pesquisa com publicação de resultados; corpos diretivos de comitês em associações científicas internacionais de grande relevância para a área; presença de bolsistas doutores ou em treinamento sabático no programa; obtenção de bolsas de pesquisa ou financiamento de agências internacionais; participação de docentes em bancas no exterior; participação na consultoria e julgamento de editais internacionais; estágios de formação pós-doutoral no exterior; oferta de cursos e colaboração em atividades de ensino em instituições de reconhecido nível de excelência no exterior; teses orientadas no exterior ou em cotutela.

- Consolidação, liderança nacional e nucleação: o programa deve formar recursos humanos para a pesquisa e a pós-graduação com expressiva formação de doutores; ter um fluxo consolidado de entrada e titulação de Mestres e Doutores; apresentar capacidade de nucleação com egressos contratados em instituições de ensino e/ou pesquisa e vinculados a programas de pós-graduação como docentes e orientadores e com a estruturação de outros PPGs; ter elevada proporção de docentes do núcleo permanente com bolsas e financiamentos para pesquisa; ter grande integração e solidariedade com outros programas com vistas ao desenvolvimento da pesquisa e da pós-graduação; participar da coordenação de Redes de Pesquisa e Pós-Graduação de abrangência nacional.

- Produção científica com inserção internacional: a produção científica com inserção internacional compreende a publicação de resultados de pesquisa, sob a forma de artigos em periódicos científicos correspondentes aos estratos A1, A2 e B1 do Qualis Periódicos da Área de Sociologia e em livros e capítulos de livros qualificados correspondentes ao estrato L4.

Por fim, vale a pena ressaltar os principais desafios colocados para a inserção e consolidação da Sociologia Brasileira no cenário mundial. O desenvolvimento de pesquisas comparativas internacionais é, sem dúvida, o passo mais importante para a inserção do Brasil no contexto de produção intelectual mundial. Nesse sentido, cabe enfatizar que todos os temas de pesquisa têm relevância internacional, ainda que tratem de questões nacionais ou locais, desde que tragam avanços teóricos ou metodológicos. Se reconhecer- 
mos que a matemática é uma 'linguagem' universal, apontando assim uma vantagem das ciências exatas para a internacionalização, podemos argumentar que a teoria sociológica e a metodologia de pesquisa também correspondem a um repertório universal.

A ausência de pesquisas comparativas não é uma especificidade do Brasil, mas das Ciências Humanas. Mas as formas de análise científica são dinâmicas e, portanto, as resistências a estudos comparativos podem ser, paulatinamente, modificadas. A forma de análise comparativa adotada na área de Políticas Públicas poderia, por exemplo, ser adaptada ao contexto dos estudos cultural-etnográficos para abordagens 'contrastivas', evitando assim o que é visto como 'achatamento cultural' do comparativo e focando no reconhecimento de diferenças/aspectos locais, os quais podem ser de grande valia para políticas internacionais e intercâmbios culturais.

Há muitos bancos de informações, quantitativas e qualitativas, a disposição de pesquisadores interessados em desenvolver análises comparadas. Mas é fundamental recordar que as análises devem evitar associações assimétricas que têm pautado algumas relações no eixo sul-norte. Os pesquisadores brasileiros precisam entrar nas pesquisas comparadas em condições simétricas e iguais de colaboração. Desse modo, é interessante expandir as relações com países do sul, sem ignorar as relações já estabelecidas com países mais consolidados na esfera acadêmica.

Por último, é imperativo abrir as instituições brasileiras para profissionais e estudantes estrangeiros. A internacionalização da academia é impossível quando há um fechamento do mercado de trabalho para absorção de pesquisadores de outros países. O maior indicador de internacionalização das instituições, na esfera global, é a capacidade de atração de estrangeiros. No entanto, mantemos nosso mercado acadêmico relativamente fechado devido, entre outras barreiras colocadas pelas instituições, às dificuldades colocadas pela burocracia das universidades e centros de pesquisa, processos de concursos públicos para seleção de docentes e discentes e resistência à adoção do inglês nas bibliografias e aulas das disciplinas.

A despeito dos entraves e desafios à internacionalização, brevemente expostos neste artigo, ela está em processo e é crescentemente reconhecida como horizonte inexorável caso a ciência brasileira, e a sociologia em particular, queira alcançar maior expressão, legitimidade e reconhecimento mundiais. Em um mundo globalizado, fronteiras nacionais e culturais têm 
sido fortemente tensionadas por trânsitos e trocas crescentes que enriquecem a produção sociológica brasileira, estendendo seu alcance investigativo, densidade analítica assim como seu público.

Em um mundo globalizado, a internacionalização se torna força motriz, não somente no campo científico, mas na vida social. Isto posto, a Sociologia deve cumprir sua vocação e oferecer o conhecimento que permita aos atores sociais compreender e se movimentar nesse cenário. Se, na segunda metade do século XX, foram superados os desafios iniciais de formar quadros profissionais e produzir pesquisas qualificadas segundo os padrões mais elevados, agora a sociologia brasileira está pronta para articular estratégias de superação das barreiras que ainda a impedem de ser reconhecida mundialmente como integrante da melhor e mais qualificada elite disciplinar.

\section{Referências}

CARDOSO, Fernando Henrique; FALETTO, Enzo. (1970 [1967]), Dependência e desenvolvimento na América Latina: ensaio de interpretação sociológica. Rio de Janeiro: LCT.

CONNELL, Raewyn. (2015), Social Science on a World Scale: connecting the Page. Sociologies in Dialogue - Sociedade Brasileira de Sociologia, v. 1, n. 1, pp. 1-16.

DWYER, Tom (2013), Reflexões sobre a internacionalização da Sociologia Brasileira. Revista Brasileira de Sociologia, v. 1, n. 1, pp.57-86.

MISKOLCI, Richard; CORTÊS, Soraya Vargas; SCALON, Celi; SALATA, André. (2016), Sociologies in Dialogue. Sociologies in Dialogue - Sociedade Brasileira de Sociologia, v. 1, n. 2, pp.1-15.

ORTIZ, Renato. (2016), Internationalization of Social Sciences: a reflection. In: Sociologies in Dialogue - Sociedade Brasileira de Sociologia, v. 1, n. 2, pp. 31-45. 